Screening

\section{Antenatal screening for syphilis}

\section{Beng T Goh, Alicia C Thornton}

\section{Congenital syphilis is preventable if the mother's infection is diagnosed early in pregnancy and treated promptly}

$\mathrm{T}$ he morbidity and mortality associated with congenital syphilis are preventable; screening in pregnancy enables treatment of the mother, fetus and sexual partners. Maternal syphilis leads to stillbirth, prematurity, clinical congenital syphilis and infant death, with the highest transmission rates and most deaths occurring in early syphilis. A recent study in Russia showed that $26 \%$ of infants with congenital syphilis had fatal outcomes, ${ }^{1}$ while $51 \%$ of all stillbirths in Tanzania were attributed to syphilis. ${ }^{2}$ While maternal screening and treatment of syphilis are extremely cost-effective health interventions even when the prevalence of infection is very low, ${ }^{3}$ many countries do not have universal antenatal screening. In a survey of 22 countries in sub-Saharan Africa, 17 had antenatal screening, but although $73 \%$ of pregnant women had antenatal care, only $38 \%$ were screened for syphilis. ${ }^{5}$

Globally, the World Health Organization (WHO) estimates that around 360000 fetal and perinatal deaths occur annually due to syphilis and a further 270000 babies suffer serious and permanent effects. ${ }^{6}$ A study conducted in four countries (Argentina, Cuba, Saudi Arabia and Thailand) participating in the WHO antenatal care trial estimated an overall prevalence of $0.9 \%$ with a range of $0.1 \%$ to $2.2 \%$ across the four countries. ${ }^{7}$ Much higher prevalence has been reported in other developing countries, for example, a prevalence of $7.7 \%$ has been described in Tanzania. ${ }^{3}$ Cheng et al ${ }^{8}$ report in this issue on the screening of half a million pregnant women in China. Syphilis was detected in 2208 (0.46\%) women and the authors showed that screening was effective in preventing congenital syphilis. Although prevalence is low nationally, the sheer size of the population in China means that there are likely to be very many cases of congenital syphilis.

Far less congenital syphilis is seen in the developed world. In the UK, only 14 cases of congenital syphilis in infants under 2 years old were reported from genitourinary medicine (GUM) clinics in 2005. ${ }^{9}$ These low figures are partially due to a well established antenatal screening programme and low rates of syphilis in heterosexual women, although rates are increasing. The constantly changing epidemiology of syphilis in the adult population highlights the need for continued compliance with the universal screening policy.

In light of this substantial burden of disease, the WHO recommends that all pregnant women should be screened at their first antenatal visit and that the test should be repeated early in the third trimester. ${ }^{70}$ Treponemal tests such as EIA or TPPA/ TPHA or cardiolipin tests such as RPR/ VDRL are used for screening. The latter test diagnoses early syphilis but misses many cases of late syphilis and there may be problems with biological false positives if no confirmatory test is performed as well as false negative in early syphilis from the prozone phenomenon.

Decentralisation of antenatal care may assist in the uptake of screening. Some of the problems are late presentation to antenatal clinic and failure to reattend for results and treatment. However, the advent of point of care (POC) treponemal tests enables immediate diagnosis and treatment at the initial visit. The POC test has to be affordable, sensitive, specific, user-friendly, rapid/robust, equipment-free and deliverable (ASSURED), ${ }^{11}$ and has to be accompanied by immediate treatment provision. A South African study showed that "complicated" RPR POC tests, although they reduced treatment delay, did not lead to a better treatment rate or a reduction in perinatal mortality. This may be due to the poor treatment rate of $64 \%$ resulting from women not staying because of the delay between testing and treatment. ${ }^{12}$ Significantly more cases are detected and treated when POC tests with immediate results are used. ${ }^{7}$ Treponemal and POC tests cannot differentiate between new and previously treated syphilis and RPR/VDRL titres are required to assess reinfection or recrudescence.

Minimum treatment is a single injection of IM benzathine penicillin 2.4 MU for early syphilis and possibly a further injection before delivery. ${ }^{30}$ However, there is a need for single dose oral treatment. While azithromycin $2 \mathrm{~g}$ orally is effective for adults, ${ }^{13}$ it is not recommended for pregnant women because poor placental penetration means that the fetus is not adequately treated. There is also concern regarding macrolide resistant strain ${ }^{14}$ and if a macrolide is used the baby should also be treated at birth. It is essential that partners are treated to prevent reinfection as otherwise the prevention efforts will be undone.

Despite the relative ease of screening and treatment, many challenges remain. Problems in developing countries include depleted stocks of drugs and other consumables, lack of appropriate transportation of samples for testing, little training for laboratory staff in performing the tests and a high turn-over of clinical staff. ${ }^{15}$ In addition, the biggest challenge is an inadequate healthcare infrastructure. In order for congenital syphilis to be prevented, a woman must access antenatal care early in her pregnancy, undergo a test, get the test results and receive treatment. Women can be lost at all these stages. Women in developing countries may live far from a healthcare facility or be unable to afford transport costs and therefore be unable to attend, while in the developed world high rates of immigration may result in groups of women being unaware of the healthcare options available to them.

All cases of congenital syphilis are preventable if the mother's infection is diagnosed and treated promptly. However, in order for this to occur good pathways of care must be in place and sufficient resources must be available. This requires commitment from governments and strong programme leadership, as shown by Cheng et al. ${ }^{8}$ The expansion and improvement of free antenatal care should be a priority followed by a specific commitment to prevent congenital syphilis. As high priority is already given to the prevention of vertical transmission of HIV, there is great potential for the integration, expansion and improvement of syphilis programmes. The WHO Millennium Development Goals of reducing the mortality of children under 5 years of age by $66 \%$ and improving maternal health by 2015 present a significant challenge and opportunity: the prevention of congenital syphilis is an integral aspect of these aims and requires leadership action.

Sex Transm Infect 2007;83:345-346.

doi: $10.1136 /$ sti.2007.026633

Authors' affiliations

Beng T Goh, The Ambrose King Centre, The Royal London Hospital, Whitechapel, London, UK Alicia C Thornton, The Health Protection Agency, London, UK

Correspondence to: Beng T Goh, The Ambrose King Centre, The Royal London Hospital, Whitechapel, London, EI 1BB UK; beng.goh@bartsandthelondon.nhs.uk

Competing interests: None declared.

See linked article p 347 


\section{REFERENCES}

1 Tikhonova L, Salakhov E, Southwick K, et al Congenital syphilis in the Russian Federation: magnitude, determinants and consequences. Sex Transm Infect 2003;79:106-10.

2 Watson-Jones D, Changalucha J, Gumodoka B, et al. Syphilis and pregnancy outcomes in Tanzania. I. Impact of maternal syphilis on outcome of pregnancy in Mwanza Region, Tanzania. J Infect Dis 2002; 186:940-7

3 Watson-Jones D, Gumodoka B, Weiss H, et al. Syphilis in pregnancy in Tanzania. II. The effectiveness of antenatal screening and single dose benzathine penicillin treatment for the prevention of adverse pregnancy outcomes. J Infect Dis 2002;186:948-57.

4 Schmid G. Economic and programmatic aspects of congenital syphilis prevention. Bull World Health Organ 2004;82(6):402-9.

5 Gloyd S, Chai S, Mercer MA. Antenatal screening in sub-Saharan Africa: missed opportunities for mortality reduction. Health Policy Plan 2001 ; 16:29-34
6 Finelli L, Berman SM, Koumans EH, et al. Congenital syphilis. Bull World Health Organ 1998;76(Suppl 2):126-8.

7 Lumbiganon P, Piaggio G, Viller J, et al. The epidemiology of syphilis in pregnancy. Int J STD AIDS 2002; 13:486-94.

8 Cheng JQ, Zhou H, Hong FC, et al. Syphilis screening and intervention of 500,000 pregnant women in Shenzhen, the People's Republic of China. Sex Transm Infect 2007;83:347-50.

9 Health Protection Agency. KC60 data tables. All new diagnoses made at genitourinary medicine (GUM) clinics: 1996-2005, United Kingdom and country specific tables. http://www.hpa.org.uk/ infections/topics az/hiv and sti/epidemiology/ 2005data/new_diagnoses_1996_2005_AR.pdf (accessed 2 July 2007)

10 World Health Organization. Sexually transmitted and other reproductive tract infections - a guide to essential practice. http://www.who.int/ reproductive-health/publications/rtis_gep/ index.htm (accessed 2 July 2007)

\section{Journal impact factors for 2006}

\section{Rob Miller, Helen Ward}

\section{Sexually Transmitted Infections flies even higher}

mpact factors for journals for the year 2006 have recently been published and we are delighted to report that the impact factor for Sexually Transmitted Infections has again increased, from 2.668 in 2005, to 3.395 in 2006 (fig 1). Sexually Transmitted Infections is now ranked 13th of 47 journals in the category "infectious diseases." It is now the highest ranked sexually transmitted infections specialty journal in terms of impact factor and has overtaken Sexually Transmitted Diseases (table 1). The journal impact factor for 2006 reflects the number of citations in 2006 to papers published in Sexually Transmitted Infections in 2004 and 2005.

Over the past few years the journal has received an increasing number of high quality submissions and is able to publish the very best of these. The quality of published articles is reflected in the fact they are highly cited. ${ }^{1-15}$ The Bench $>$ Press system facilitates online submission and Online First enables us to publish an

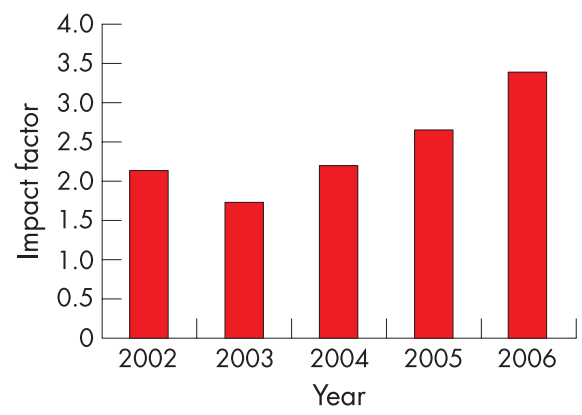

Figure 1 Impact factors for Sexually Transmitted Infections, 2002-6. accepted paper "online" within a few days of accepting it and in advance of subsequent publication in the paper journal. ${ }^{16}$ As editors we urge you to send us your best submissions. By doing so you will enable us to publish articles of a high standard throughout 2007, 2008, and beyond and further enable us to continue to build on the success achieved with Sexually Transmitted Infections.

Sex Transm Infect 2007;83:346.

doi: 10.1136/sti.2007.026971

\section{Authors' affiliations}

R F Miller, H Ward, Sexually Transmitted Infections Editorial Office, BMJ Journals, BMA House, London, UK

Correspondence to: Professor R F Miller, Sexually Transmitted Infections Editorial Office, BMJ Journals, BMA House, Tavistock Square, London WCIH 9HR, UK; sti@bmigroup.com

\section{REFERENCES}

1 Van Bergen J, Gotz HM, Richardus JH, et al. Prevalence of urogenital Chlamydia trachomatis

Table 1 Specialty journal impact factors for 2006 (published in 2007)

\begin{tabular}{ll}
\hline Journal & $\begin{array}{l}\text { Impact } \\
\text { factor }\end{array}$ \\
\hline Sexually Transmitted Infections & 3.395 \\
Sexually Transmitted Diseases & 2.577 \\
International Journal of STD \& & 1.274 \\
AIDS & \\
\hline
\end{tabular}

11 Peeling RW, Holmes KK, Mabey D, et al. Rapid tests for sexually transmitted infections (STIs): the way forward. Sex Transm Infect 2006;82(Suppl V):v1-v6.

12 Myer L, Wilkinson D, Lombard C, et al. Impact of on-site testing for maternal syphilis on treatment delays, treatment rates, and perinatal mortality in rural South Africa: a randomised controlled trial. Sex Transm Infect 2003:79:208-13.

13 Hook EW, Nartin DH, Stephens J, et al. A randomized, comparative pilot study of azithromycin versus benzathine penicillin $G$ for treatment of early syphilis. Sex Transm Dis 2002;29:486-90

14 Lukehart SH, Godornes C, Molini BJ, et al. Macrolide resistance in Treponema pallidum in the United States and Ireland. N Engl J Med 2004;351:154-8.

15 Deperthes BD, Meheus A, O'Reillty K, et al. Maternal and congenital syphilis programmes: case studies in Bolivia, Kenya and South Africa. Bull World Health Organ 2004;82:410-6.

increases significantly with level of urbanisation and suggests targeted screening approaches: results from the first national population based study in the Netherlands. Sex Transm Infect 2005;81:17-23.

2 Gotz HM, van Bergen JE, Veldhuijzen IK, et al. A prediction rule for selective screening of Chlamydia trachomatis infection. Sex Transm Infect 2005;81:24-30.

3 Weiss HA, Thomas SL, Munabi SK, et al. Male circumcision and risk of syphilis, chancroid, and genital herpes: a systematic review and metaanalysis. Sex Transm Infect 2006:82:101-9.

4 French $\mathrm{P}$, Ison CA, Macdonald N. Lymphogranuloma venereum in the United Kingdom. Sex Transm Infect 2005;81:97-8.

5 Van der Bii AK, Stolte IG, Coutinho RA, et al. Increase of sexually transmitted infections, but not $\mathrm{HIV}$, among young homosexual men in Amsterdam are STIs still reliable markers for HIV transmission? Sex Transm Infect 2005;81:43-7.

6 Hesketh T, Duo L, Li H, et al. Attitudes to HIV and HIV testing in high prevalence areas of China: informing the introduction of voluntary counselling and testing programmes. Sex Transm Infect 2005;81:108-12.

7 García-Calleja JM, Gouws E, Ghys PD. National population based HIV prevalence surveys in subSaharan Africa: results and implications for HIV and AIDS estimates. Sex Transm Infect 2006:82(Suppl 3):iii64-70.

8 Minnis AM, Padian NS. Effectiveness of female controlled barrier methods in preventing sexually transmitted infections and HIV: current evidence and future research directions. Sex Transm Infect 2005;81:193-200

9 Meyer T, Arndt R, von Krosigk A, et al. Repeated detection of lymphogranuloma venereum caused by Chlamydia trachomatis L2 in homosexual men in Hamburg. Sex Transm Infect 2005;81:91-2.

10 Brown T, Grossly NC, Garnett G, et al. Improving projections at the country level: the UNAIDS Estimation and Projection Package 2005. Sex Transm Infect 2006;82(Suppl 3):iii34-40.

11 Anagrius C, Loré B, Jensen JS. Mycoplasma genitalium: prevalence, clinical significance, and transmission. Sex Transm Infect 2005;81:458-62.

12 Chen MY, Fairley CK, Donovan B. Discordance between trends in chlamydia notifications and hospital admission rates for chlamydia related diseases in New South Wales, Australia. Sex Transm Infect 2005:81:318-22

13 Aguilar LV, Lazcano-Ponce E, Vaccarella S, et al. Human papillomavirus in men: comparison of different genital sites. Sex Transm Infect 2006:82:31-3.

14 Aldrich T, Becker D, Garcia SG, et al. Mexican physicians' knowledge and attitudes about the human papillomavirus and cervical cancer: a national survey. Sex Transm Infect 2005;81:135-41.

15 Lyerla R, Gouws E, García-Calleja JM, et al. The 2005 Workbook: an improved tool for estimating HIV prevalence in countries with low level and concentrated epidemics. Sex Transm Infect 2006;82(Suppl 3):41-4.

16 Miller RF, Ward H. Online First in Sexually Transmitted Infections. Sex Transm Infect 2006;82:190. 